\section{INTRAOPERATIVE POSITIONING TO PREVENT DRIVELINE INSULATION FROM ACTING AS A CONDUIT FOR LEFT VENTRICULAR ASSIST DEVICE POCKET INFECTION \\ To the Editor:}

The recent case report from Pinninti and colleagues ${ }^{1}$ describes an interesting source for left ventricular assist device infection related to simultaneous breaks in the internal and external portions of the driveline coating that permitted an ascending infection. Although this is a rare event, maneuvers to prevent it may be worthwhile because intraoperative positioning of the driveline may be an important factor in its occurrence. During my time at Hahnemann University Hospital, we had 2 such cases, both early in our experience with the HeartMate 2 device (Thoratec Corporation, Pleasanton, Calif). Both our patients were obese men in whom the driveline had been implanted in a manner similar to that shown in the radiograph provided by Pinninti and colleagues ${ }^{1}$ (no loop), and both gained weight after implantation. Both were seen with an external driveline tear that was repaired. Both underwent successful device exchange after an internal infection was documented, and both were found to have a disruption of the covering on the internal portion of the driveline that was considered to be the source of the pocket infection.

\footnotetext{
The Editor welcomes submissions for possible publication in the Letters to the Editor section that consist of commentary on an article published in the Journal or other relevant issues. Authors should: - Include no more than 500 words of text, three authors, and five references. - Type with double-spacing. - See http://jtcs.ctsnetjournals.org/misc/ifora.shtml for detailed submission instructions. - Submit the letter electronically via jtcvs.editorialmanager.com. Letters commenting on an article published in the JTCVS will be considered if they are received within 6 weeks of the time the article was published. Authors of the article being commented on will be given an opportunity of offer a timely response ( 2 weeks) to the letter. Authors of letters will be notified that the letter has been received. Unpublished letters cannot be returned.
}

Thoratec modified the driveline to reinforce the area where the driveline enters the pump, and this was done mainly to decrease wire fracture at this point. Leaving a loop in the driveline is already recommended to decrease the risk of wire fracture further, but this may also decrease the rate of the type of infection seen in the reported case. Our theory is that weight gain played a role in the internal driveline fracture in both our cases. Once the velour has grown into the surrounding tissues, the increasing weight of the pannus could pull on the internal driveline. Without a loop, the stress is transmitted to the point where the driveline enters the pump body. An internal loop can allow the patient to gain weight before there is tension at the pump. Once we began leaving a loop in the driveline, there were no fractures of the internal portion of the driveline.

Another interesting question is whether to seal the external portion of the driveline if there is a tear in the silicone. In our 2 cases, and the case presented in the article, repair of the external silicone layer preceded the pump pocket infection by a short time (weeks to months). If the repair had not been done, it is possible that infection might never have occurred. We continue to repair these tears to protect the driveline from further direct trauma, however, because we know that the infection rate with repair is very low.

\section{John Entwistle, $M D, P h D$ Thomas Jefferson University Philadelphia, $\mathrm{Pa}$}

\section{Reference \\ 1. Pinninti M, Tholan V, Sulemanjee NZ. Driveline insulation as a conduit for left ventricular assist device pocket infection. J Thorac Cardiovasc Surg. 2014;148:e135-6. \\ http://dx.doi.org/10.1016/ j.jtcvs.2014.07.006}

\section{Reply to the Editor:}

As mentioned by Dr John Entwistle in his letter, our patient was also obese and gained weight after left ventricular assist device implantation. This probably contributed to the relative pulling or tugging on the driveline with the increase in abdominal girth and external manipulation, resulting in breakage at the junction of the proximal portion of the intracorporeal driveline and the pump without causing any loss of skin integrity at the driveline exit site or change in the extracorporeal driveline. Leaving an internal loop, while maintaining a functional and convenient length of the extracorporeal driveline for connecting to the controller, probably would address this rare complication.

Regarding repair of the break in the external driveline with a self-adhesive tape, there are no clear data indicating whether to leave such a break open or to repair it. It is a common practice to repair it, though this is intended to prevent further damage to the electrical components and not necessarily to prevent infections. If the repair is not done, we believe that it is still possible to observe ascending infection, because the driveline has a continuous open conduit without any compartmentalization between inner and outer sheaths. Recently Schima and colleagues ${ }^{1}$ reported a case of driveline damage directly at the transcutaneous exit site that was repaired with a highly expandable, tightly adherent latex tube without any infection at 5-month follow-up. Repair of the damaged driveline under sterile conditions with a tight, expandable tube to cover the damage, as in the case of Schima and colleagues, ${ }^{1}$ or compartmentalization of the proximal driveline may prevent ascending driveline infections.

Mamatha Pinninti, MD

Vinay Thohan, MD

Nasir Sulemanjee, MD

Aurora Cardiovascular Services Aurora Sinai/Aurora St. Luke's Medical Centers 
University of Wisconsin School of Medicine and Public Health

Milwaukee, Wis

\section{Reference \\ 1. Schima H, Stoiber M, Schlöglhofer T, Hartner Z, Haberl T, Zimpfer D. Repair of left ventricular assist device driveline damage directly at the transcutaneous exit site. Artif Organs. 2014;38: 422-5.}

http://dx.doi.org/10.1016/ j.jtcvs.2014.09.005

\section{MISUSE OF THE TERM "SUBCLAVIAN ACCESS"} To the Editor:

In a recent issue of the Journal, there was an article by Ramlawi and colleagues ${ }^{1}$ entitled, "Direct aortic and subclavian access for transcatheter aortic valve replacement: Decision making and technique." I was enthusiastic to read the article because the title potentially indicated a description of a novel access for transarterial aortic valve implantation through direct puncture for access of the subclavian artery. I was a bit disturbed to realize that Ramlawi and colleagues $^{1}$ do not actually use or expose the subclavian artery, but in fact the axillary artery. Per anatomic definition, the subclavian artery extends to the lateral border of the first rib, where it becomes the axillary artery, which in turn becomes the brachial artery after passing the lower margin of the major teres muscle. Both from their figure and the description (incision in the deltopectoral groove), it is obvious that Ramlawi and colleagues ${ }^{1}$ use the axillary artery as access site and not the subclavian artery. They depict the same approach as vascular surgeons use when performing axillofemoral bypass grafting. ${ }^{2}$ The usual access to the subclavian artery is by a supraclavicular incision, as used in deviation surgery before implantation of endovascular aortic arch grafts. The message is that we should be accurate in the use of medical terms when reporting on anatomic structures with precisely defined names.

Sven M. Almdahl, MD, PhD

Department of Cardiothoracic and Vascular Surgery

University Hospital of North Norway Troms $\phi$, Norway

\section{References}

1. Ramlawi B, Bedeir K, Barker C, Lin $\mathrm{CH}$, Kleiman N, Reardon M. Direct aortic and subclavian access for transcatheter aortic valve replacement: Decision making and technique. J Thorac Cardiovasc Surg. 2014;148:353-6.

2. Kuo HN, Lai HC, Chang YW, Wang CC, Lee WL, Chan SW, et al. Axillofemoral bypass relieves visceral malperfusion in type B aortic dissection. Ann Thorac Surg. 2013;95:703-5.

3. Xydas S, Wei B, Takayama H, Russo M, Bacchetta M, Smith CR, et al. Use of carotid-subclavian arterial bypass and thoracic endovascular aortic repair minimize cerebral ischemia in total aortic reconstruction. J Thorac Cardiovasc Surg. 2010;139:717-22; discussion 722.

\section{http://dx.doi.org/10.1016/} j.jtcvs.2014.07.013

\section{Reply to the Editor:}

We appreciate Almdahl's contribution. His letter describes concern about arterial access nomenclature, defining subclavian artery access as supraclavicular and stating that our approach, which is infraclavicular, is axillary rather than subclavian.

From an anatomic standpoint, the subclavian, axillary, and brachial arteries represent a continuum starting from the point of emergence of the subclavian artery in the chest and extending to the terminal branching of the brachial artery in the antecubital fossa. Three anatomic territories are limited by the inferior border of the first rib and that of the teres major muscle. Further divisions into thirds of the subclavian and axillary arteries are defined relative to the scalenus anterior and the pectoralis minor muscles, each passing anterior to the second portion of the respective artery of interest.

The subclavian artery can in fact be accessed through either a supraclavicular or an infraclavicular approach. With the latter approach, the infraclavicular portion of the subclavian artery is accessed through an incision in the Mohrenheim fossa, through the pectoralis major fibers. The deltopectoral fascia is accessed cranial and medial to the pectoralis minor muscle, exposing the area of the vessel between the lateral border of the scalenus anterior and the medial border of the pectoralis minor. This fully exposes the third part of the subclavian artery, transitioning into the first part of the axillary artery. A clear distinction between these zones bears little importance for the procedural technique, and individual surgeons are encouraged to choose the puncture point with which they are most comfortable.

We described our technique as an infraclavicular yet still a distal subclavian puncture, and this has been similarly described by a number of other authors. ${ }^{1-4}$ This same infraclavicular approach has also been described for subclavian access for balloon pump insertion. Almdahl's point is very well taken. Axillary access also describes how some surgeons would opt to access the vessel. For future use, we believe that the most anatomically descriptive nomenclature for the infraclavicular approach would be the term subclavian/axillary access, as described in a few reports. ${ }^{6,7}$

We again thank Almdahl for his enriching contribution.

Basel Ramlawi, $M D$

Kareem Bedeir, $M B C h B, M S$

Michael Reardon, $M D$

Methodist DeBakey Heart and

Vascular Center

Houston, Tex

\section{References}

1. Petronio AS, De Carlo M, Bedogni F, Marzocchi A, Klugmann S, Maisano F, et al. Safety and efficacy of the subclavian approach for transcatheter aortic valve implantation with the CoreValve revalving system. Circ Cardiovasc Interv. 2010;3:359-66. 